Submission ID: 43892

\title{
Integration of 3D TEM and 3D Seismic for Prediction of Reservoir Properties
} and Saturation

O. Tokareva* (IERP), P. Mostovoy (GPN-NTC), A. Ostankov (GPN-NTC), D. Orlova (IERP), V.

Gomulsky (IERP), S. Kompaniets (IERP)

\section{SUMMARY}

The paper presents various approaches to the interpretation of the data of 3D TEM for the predicting of reservoir properties and saturation of clastic horizons with using data of the wellbore testing, petrophysical functions and well logging. Presents opportunities to increase the efficiency of the productive reservoir prediction based on data integration 3D TEM and 3D seismic data. 


\section{Возможности интеграции данных ЗСБ в геологическую модель целевых горизонтов коллекторов}

Токарева О.В. (АО «ИЭРП»), Мостовой П.Я. («ГПН-НТЦ»), Останков А.В. («ГПН-НТЦ»), Орлова Д.А. (АО «ИЭРП»), Гомульский В.В. (АО «ИЭРП»), Компаниец С.В. (АО «ИЭРП»).

\section{Введение}

Карбонатные и терригенные отложения подсолевого комплекса в пределах Непскоботуобинской антеклизы характеризуются сложным геологическим строением: ловушки неантиклинального типа, малая мощность коллекторов и диагинетические преобразования (засолонение и карбонатизация). Для повышения качества прогноза на стадии детальных поисков и разведки выполняется комплекс ГРР включающий в себя: 3D сейсморазведочные (СРР) и высокоплотные электроразведочные (ЭРР) исследования по единой сети наблюдения.

Традиционно на основе данных СРP формируется структурный каркас и прогноз характеристик коллектора. На удельное сопротивление (УЭС) в большей степени влияет объем свободной воды в пласте, что позволяет оценивать положение ВНК в блоке по данным ЭРР. Формирование комплексного прогноза по результатам двух методов требует разработки методики интеграции данных электромагнитных исследований ЗСБ в геологическую модель. Одним из осложнений является то, что разрешающая способность метода ЗСБ ниже, чем МОГТ, где целевой пласт мощностью 20 м приурочен к геоэлектрическому горизонту толщиной около $70-100$ м. Таким образом, важной задачей является оценка вклада проводимости целевого пласта в суммарную проводимость геоэлектрического горизонта и определение геоэлектрических параметров вмещающих пород, характеризующихся наименьшей изменчивостью.

Применение электромагнитных исследований направлено для решения задач разделения зон ЧВЗ и ВНЗ, а так же для оконтуривания зон с ухудшенными характеристиками коллекторов.

\section{Подходы к комплексированию данных ЭРР и СРР}

Геологическая модель целевых горизонтов формируется на основе данных сейсморазведочных работ и результатов бурения скважин. Одной из ряда неопределенностей, закладываемых в геологическую модель, является положение ВНК. Поскольку удельное электрическое сопротивление, параметр чувствительный к наличию свободной воды, то учет результатов электромагнитных исследований в комплексной геологической модели, позволит сузить неопределенность насыщения пласта.

В основе комплексирования данных ЗСБ и МОГТ лежит использование структурного каркаса определенного по МОГТ при инверсии данных ЗСБ, для фиксирования толщин геоэлектрических горизонтов и, тем самым, снижения числа эквивалентных решений в ходе инверсии.

Существует ряд подходов к прогнозированию на основе комплекса данных ЗСБ и МОГТ. Первый подход заключается в простом наложении аномалий, связываемых с перспективными зонами по обоим методам. Перспективные зоны по ЗСБ традиционно определялись на основе сопоставления значений сопротивления/проводимости геоэлектрического горизонта и результатов испытаний скважин. В результате чего формировалось граничное значение параметра коллектор/неколлектор. Затем выполняется сопоставление аномалий с перспективными объектами по сейсморазведке.

Второй способ комплексирования заключается в анализе изменения значений сопротивления геоэлектрического горизонта по ЗСБ в рамках выявленной перспективной аномалии по данным МОГТ. Для разреза отложений терригенного венда благоприятным фактором является понижение значений сопротивления в направлении погружения структурной поверхности 
(рис.1). Наибольший контраст значений сопротивления будет прослеживаться в блоках с наличием флюидоконтакта нефть-вода или газ-вода.

Недостатком данных подходов является отсутствие количественного прогноза насыщения коллекторов
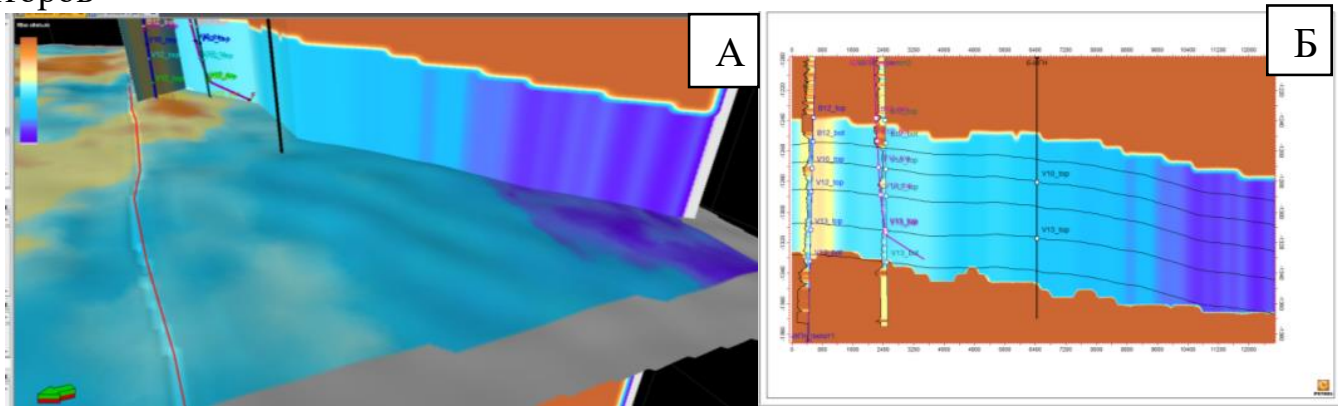

Рисунок 1 Геоэлектрическая характеристика целевого интервала. A - карта продольного сопротивления; $Б$ - фрагмент геоэлектричсекого разреза

Переход к количественному прогнозу осуществлен в методике «РоКЭС», в основе которой лежит петрофизическая зависимость связи УЭС и объема порового пространства (Кп, Нэф), насыщенного флюидом (Кв). Наиболее часто используется зависимость Дахнова-Арчи. По результатам инверсии МОГТ формируются прогнозная модель эффективных толщин и коэффициентов пористости. Прогнозная модель сопротивления коллектора определяется по результатам электромагнитных исследований ЗСБ. Переход к прогнозным значениям параметра насыщения осуществляется через петрофизическую зависимость.

Преимуществом данного подхода является объединение в прогнозной модели результатов двух методов наземных геофизических исследований, что сужает диапазон неопределенности по ключевым прогнозным параметрам: Нэф, Кп, Кв.

\section{Методика прогнозирования «РоКЭС»}

Методика прогнозирования заключается в том, что прогнозная геоэлектрическая модель коллектора по данным ЗСБ является «фильтром» геологических моделей, реализуемых на основе результатов МОГТ и ГИС (рис. 2). Применяя данный подход, возможно прогнозировать насыщение коллекторов (сузить диапазон неопределенности положения ВНК), а также в пределах блока с выдержанными значениями насыщения возможно по изменению значений сопротивления корректировать емкостную модель строения коллектора.
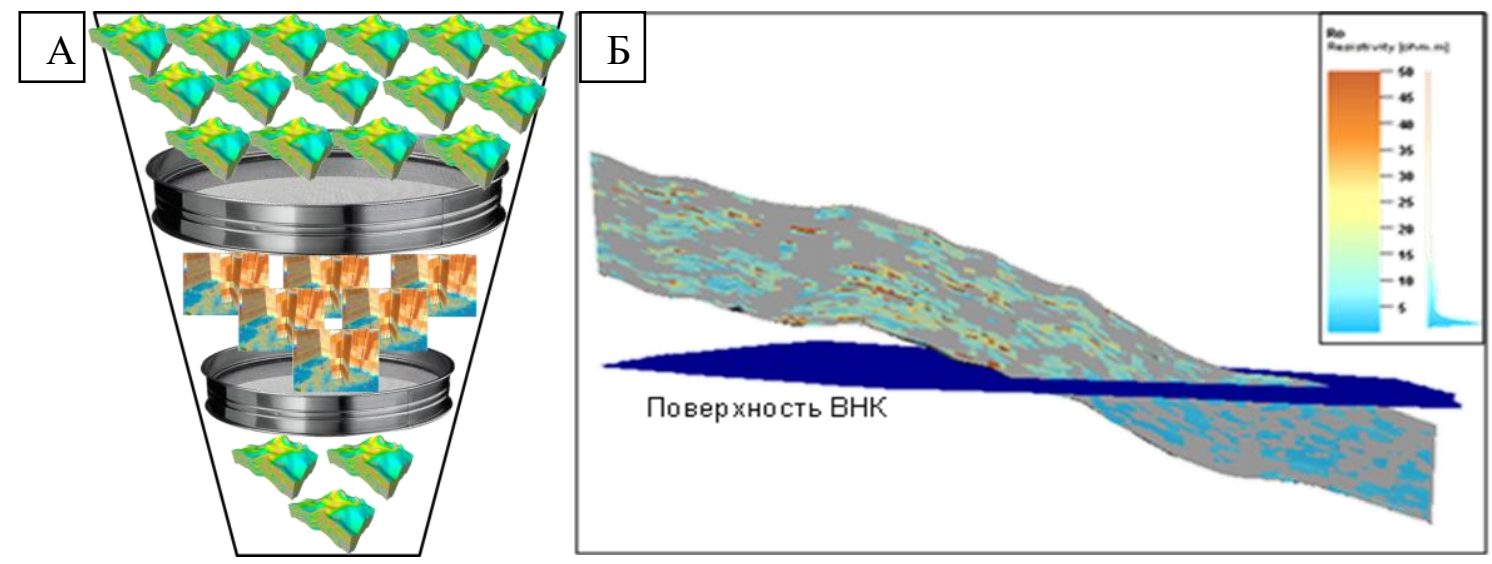

Рисунок 2 Геологические модели. А - Фильтр геологических моделей; Б-Геологогеоэлектрическая модель пласта

Методика включает в себя ряд ключевых этапов: первый - сопоставление УЭС БК-ЗСБ; второй - расчет прогнозной модели сопротивления/проводимости коллектора по ЗСБ; третий сопоставление прогнозной геоэлектрической модели коллектора по ЗСБ и геоэлектрической 
модели на основе прогнозной геологической модели; четвертый - выбор ключевых неопределенностей и алгоритма компенсации; пятый - анализ итоговой геологической модели с учетом данных ЭРР.

Предпосылкой для сравнения результатов ЗСБ и БК послужила разработка методики количественного прогноза насыщения и параметров коллекторов по результатам наземных электромагнитных исследований ЗСБ. Выполнено сравнение значений сопротивления по 20 скважинам. Для корректного сопоставления значений сопротивления геоэлектрического горизонта по ЗСБ и диаграммы БК проведен анализ и выбран оптимальный способ осреднения. Выявлено, что на характер распределения влияет, величина зонда установки БК. В скважинах пробуренных в 80-е годы использовали малые размеры зонда, соответственно прослеживалось большее влияние зоны проникновения, чем для скважин «нового» фонда (2011 - 2017 гг). Отчетливо разделились выборки по скважинам «нового» фонда $(2011-2017$ гг) и скважины «старого» фонда. Корреляция между значениями сопротивления составляет 0.8 . Учитывая высокую корреляцию, для увязки площадной модели сопротивления целевого горизонта по ЗСБ и данных ГИС через уравнение регрессии выполнена нормализация карты продольного сопротивления. Данное построение является основой для последующего моделирования.

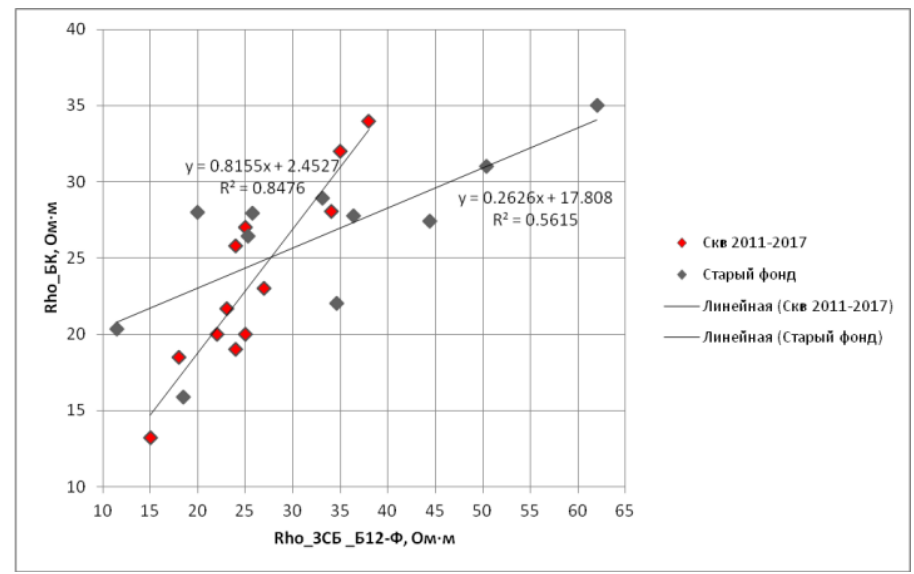

Рисунок 3 Диаграмма связи значений сопротивления интервала Б12-Ф ЗСБ и БК

Прогнозная модель сопротивления/проводимости коллектора с учетом данных ЗСБ определяется как разница проводимости геоэлектрического горизонта, полученная по результатам инверсии ЗСБ и проводимости вмещающих отложений. Последняя определятся на основе анализа литологии и толщины.

Одним из важных этапов является сравнение площадной геоэлектрических моделей по ЗСБ и моделей, рассчитанных на основе геологических реализации, что позволяет:

1. определить геоэлектрические параметры коллектора при различных эффективных толщинах, Кп и Кв;

2. оценить вклад проводимости коллектора в суммарную проводимость геоэлектрического слоя.

3. сравнить прогнозную проводимость коллектора с учетом данных ЗСБ и модельной проводимости интервала на основе исходных данных.

Расхождение модельных геоэлектрических параметров и прогнозных полученных с учетом данных ЗСБ позволяет принять решение о корректности принятой геологической модели (Рис. 4). 


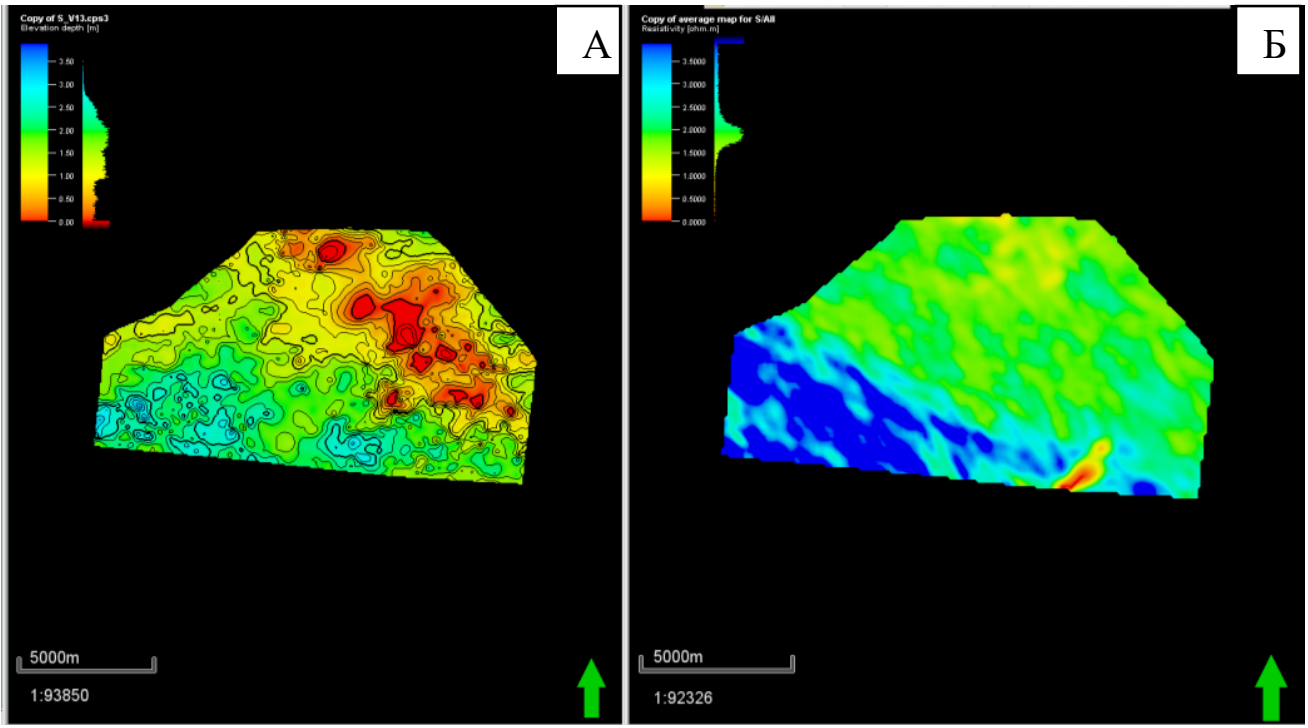

Рисунок 4 Проводимости пласта коллектора. А- по данным ЗСБ; Б-на основе исходной геологической модели.

\section{Результаты работ}

Данная методика протестирована на основе блока детальных поисков и разведки, и подтверждена при бурении куста скважин.

На основе прогнозной проводимости по данным ЗСБ с применением модели эффективных толщин и пористости по ГИС и СРР рассчитаны модели прогнозных значений Кв целевого пласта.

В распределении модельных значений коэффициента водонасыщенности выявлены некорректные распределения: на отдельных участках, расположенных выше по структурной поверхности, прослеживались высокие значения водонасыщенности. Данное наблюдение позволило в указанных местах рекомендовать «изменение» емкостных свойств коллектора, т.е. увеличение эффективной толщины/пористости. Оконтурены участки ухудшения коллекторских свойств.

Описанная методика применена для заложения двух пилотных скважин на месторождении в ВC. С учетом данных ЗСБ в геологической модели эффективные толщины были скорректированы. Прогноз был подтвержден последующим бурением.

\section{Выводы}

Использование результатов электромагнитных исследований ЗСБ в геологической модели основано на многолетнем опыте совместного комлексирования электроразведочных и сейсморазведочных методов на этапе ГРР Существующие наработки отражают перспективы развития данной методики. Представленная методика отражает возможность использования данных о геоэлектрическом строении в количественном прогнозе параметров коллекторов.

\section{Библиография}

1. Буддо И.В. Возможности электромагнитных зондирований становлением поля в ближней зоне при изучении коллекторов осадочного чехла юга Сибирской платформы. - Диссертация на соискание ученой степени кандидата геологоминералогических наук. Иркутск, 2011 г.

2. $\quad$ Геология нефти и газа Сибирской платформы. Под ред. А.Э. Конторовича, В.С. Суркова, А.А. Трофимука. // М.: «Недра». - 1981. - 552 с. 


\section{EAGE}

\section{References}

1. Buddo I.V. Possibilities of electromagnetic soundings by the formation of a field in the near zone when studying the collectors of the sedimentary cover of the south of the Siberian platform. - Thesis for the degree of candidate of geological and mineralogical sciences. Irkutsk, 2011

2. Kontorovich A.E., Surkov V.S., Trofimuk A.A. [1981] Geology of oil and gas of the Siberian platform. 552. 